\title{
Oxygen Reduction Reaction Activity of Pt/Graphene Composites with Various Graphene Size
}

\author{
Jun Sato, ${ }^{a}$ Kazuki Higurashi, ${ }^{\mathrm{a}}$ Katsutoshi Fukuda, ${ }^{\mathrm{b}}$ and Wataru Sugimoto ${ }^{\mathrm{a}, \mathrm{b}, *}$ \\ ${ }^{a}$ Faculty of Textile Science and Technology, Shinshu University (3-15-1 Tokida, Ueda, Nagano 386-8567, Japan) \\ ${ }^{\mathrm{b}}$ Collaborative Innovation Center for Nanotech Fiber, Shinshu University (3-15-1 Tokida, Ueda, Nagano 386-8567, Japan)
}

Received October 31, 2010 ; Accepted December 13, 2010

\begin{abstract}
Graphite oxide nanosheets with three different sheet sizes were prepared from different graphite materials. The graphite oxide nanosheets were used as precursors to prepare three 20 mass \% Pt/graphene composite electrocatalysts composed of different sizes of graphene. The structure and electrochemical properties in $0.1 \mathrm{M} \mathrm{HClO}_{4}$ at $60^{\circ} \mathrm{C}$ of the three Pt/graphene electrocatalysts were studied. Well dispersed Pt nanoparticles with $2.2 \mathrm{~nm}$ average diameter and electrochemically active surface area of $\sim 50 \mathrm{~m}^{2}(\mathrm{~g}-\mathrm{Pt})^{-1}$ were obtained irrespective of the size of graphene. Despite the similarity in Pt nanoparticle state, the oxygen reduction reaction was strongly affected by the size of graphene. Smaller sized graphene afforded higher mass and specific activity towards the oxygen reduction reaction.
\end{abstract}

Key Words : Pt Supported Carbon, Graphene, Oxygen Reduction Reaction, Nanosheet

\section{Introduction}

Graphene, a single layer of graphite, is a nanoscopic two-dimensional crystallite with an ultimate thickness of one carbon atom. It has attracted great interest from many researchers in recent years as a new nanocarbon. ${ }^{1,2)}$ Agglomerates of single-layered graphene with a re-stacked structure, often simply called graphene for simplicity, can be obtained in large quantities via exfoliation of graphite oxide and subsequent reduction. ${ }^{3,4}$ Due to its good electronic conductivity and theoretical surface area of $2630 \mathrm{~m}^{2} \mathrm{~g}^{-1}$, graphene may be a candidate as a new support material for Pt-based electrocatalysts. $\mathrm{Pt} /$ graphene has been reported to show good activity both as an anode and cathode in polymer electrolyte fuel cells. Promising electrocatalytic behavior has been reported for Pt/graphene prepared by impregnation methods using pre-reduced graphene aggregates or functionalized graphene. ${ }^{5-7)}$ In this work, we focused our attention on the difference in the porous structure of graphene aggregates when different size graphite oxide nanosheets are used as precursors. ${ }^{8)}$ We report here, a systematic study of $\mathrm{Pt} /$ graphene using different sized graphene in an attempt to gain insight into the effect of support structure on the catalytic behavior. Three Pt/graphene samples with the same Pt loading and particle size were prepared with different pore structure via impregnationreduction method. The oxygen-reduction reaction in acidic media was characterized. To the best of our knowledge this is the first study that has highlighted the size effect of the carbon support of Pt/graphene composites.

\section{Experimental}

Graphite oxide was prepared following the Hummers method $^{9)}$ using three different graphite material listed in Table 1. Graphite oxide (100 mg) was dispersed in 100 $\mathrm{mL}$ of ultra-pure water $(>18 \mathrm{M} \Omega \mathrm{cm}$ ) and subjected to ultrasonification in order to obtain a colloid containing exfoliated graphite oxide nanosheets. Aqueous $\mathrm{Pt}\left(\mathrm{NO}_{2}\right)_{2}\left(\mathrm{NH}_{3}\right)_{2}$ was added to the graphite oxide

Table 1 Properties of Pt/graphene obtained from different starting material.

\begin{tabular}{|c|c|c|c|c|c|c|c|c|c|}
\hline & \multirow{2}{*}{$\begin{array}{l}\text { starting } \\
\text { graphite } \\
\text { material }\end{array}$} & \multirow{2}{*}{$\begin{array}{c}\text { average } \\
\text { particle } \\
\text { size of } \\
\text { graphite }^{\text {a) }} \\
/ \mu \mathrm{m}\end{array}$} & \multirow{2}{*}{$\begin{array}{l}\text { lateral size } \\
\text { of graphite } \\
\text { oxide } \\
\text { nanosheet } \\
\text { / } \mu \mathrm{m}\end{array}$} & \multirow{2}{*}{$\begin{array}{c}\mathrm{Pt} \\
\text { loading } \\
\text { /mass \% }\end{array}$} & \multirow{2}{*}{$\begin{array}{l}\text { ECSA } \\
/ \mathrm{m}^{2} \mathrm{~g}^{-1}\end{array}$} & \multicolumn{2}{|c|}{$\begin{array}{l}\text { Mass activity } \\
/ \mathrm{A}(\mathrm{g}-\mathrm{Pt})^{-1}\end{array}$} & \multicolumn{2}{|c|}{$\begin{array}{c}\text { Specific activity } \\
\qquad / \mu \mathrm{A} \mathrm{cm}{ }^{-2}\end{array}$} \\
\hline & & & & & & $\begin{array}{l}800 \mathrm{mV} \\
\text { vs. RHE }\end{array}$ & $\begin{array}{l}850 \mathrm{mV} \\
\text { vs. RHE }\end{array}$ & $\begin{array}{l}800 \mathrm{mV} \\
\text { vs. RHE }\end{array}$ & $\begin{array}{l}850 \mathrm{mV} \\
\text { vs. RHE }\end{array}$ \\
\hline Pt/graphene-S & $\mathrm{Z}-5 \mathrm{~F}$ & $\begin{array}{c}3 \\
(1-10)\end{array}$ & $0.03-6$ & 19.8 & 55 & 247 & 143 & 450 & 260 \\
\hline $\mathrm{Pt} /$ graphene-M & $\mathrm{ACP}$ & $\begin{array}{c}23 \\
(2-100)\end{array}$ & $0.5-13$ & 19.8 & 45 & 173 & 101 & 380 & 220 \\
\hline Pt/graphene-L & $Z+80$ & $\begin{array}{c}270 \\
(150-500) \\
\end{array}$ & $>10$ & 20.9 & 48 & 92 & 60 & 190 & 120 \\
\hline
\end{tabular}

\footnotetext{
a) Average particle size and particle size distribution (shown in parenthesis) were provided from manufactures.
} 
nanosheet colloid and thoroughly mixed by ultrasonification and magnetically stirring. The solution was then slowly evaporated at $60^{\circ} \mathrm{C}$ to obtain a powder sample. The product was finally reduced at $200{ }^{\circ} \mathrm{C}$ under flowing $\mathrm{H}_{2} / \mathrm{N}_{2}$ (1:9) for $2 \mathrm{~h}$ to obtain the Pt/graphene composite electrocatalysts. The products obtained with small sized graphite (Z-5F, Ito Kokuen Co., Ltd.), medium sized graphite (ACP, Nippon Graphite Industries Ltd.), and large sized graphite $(Z+80$, Ito Kokuen Co., Ltd.) will be abbreviated as $\mathrm{Pt}$ /graphene-S, Pt/graphene- $\mathrm{M}$, and $\mathrm{Pt}$ / graphene-L. The nominal content of Pt was kept constant at 20 mass \%.

An atomic force microscope (SPA400, Seiko Instruments Inc.) and a transmission electron microscope (TEM, JEM-2010, JEOL) were used to characterize the morphology of the graphite oxide nanosheets and $\mathrm{Pt} /$ graphene composites. The structure of the electrocatalysts was characterized by X-ray diffraction. The Pt loading in the electrocatalyst was measured using thermogravimetry (Thermo plus TG8120, Rigaku).

The working electrode was prepared by depositing a controlled amount of the electrocatalyst (17.5 $\mu \mathrm{g}-\mathrm{Pt}$ $\left.\mathrm{cm}^{-2}\right)$ on a mirror-polished glassy carbon rod $(6 \mathrm{~mm}$ in diameter). Nafion ionomer was added to the dispersion as a binder. A beaker-type electrochemical cell equipped with the working electrode, a carbon felt counter electrode, and a reversible hydrogen electrode (RHE) reference electrode was used. All electrochemical measurements were conducted in $0.1 \mathrm{M} \mathrm{HClO}_{4}$ electrolyte at 60 ${ }^{\circ} \mathrm{C}$ with a rotating disk electrode (Nikko Keisoku Ltd.) connected to a potentio/galvanostat (Hokuto Denko HSV-100). Cyclic voltammograms in de-aerated electrolyte were firstly measured to estimate the electrochemical Pt surface area (ECSA) from the charge due to hydrogen adsorption. Hydrodynamic voltammograms in deaerated electrolyte was then recorded at $10 \mathrm{mV} \mathrm{s}^{-1}$ from 0.05 to $1.2 \mathrm{~V}$ vs. RHE (anodic sweep) at rotating rates of $2500,2200,1600,1200,800$, and $400 \mathrm{rpm}$ and were used as the background current. Oxygen reduction reaction (ORR) was characterized by linear sweep voltammetry in $\mathrm{O}_{2}$ saturated electrolyte from 0.05 to $1.2 \mathrm{~V}$ vs. RHE at $10 \mathrm{mV} \mathrm{s}^{-1}$ at the respective rotating sweeps.

\section{Results and Discussion}

The degree of exfoliation of the graphite oxide was characterized using atomic force microscopy (AFM). A small portion of aqueous graphite oxide colloid was deposited on a silicon substrate for the observations. Figure 1 shows the AFM images of exfoliated graphite oxide prepared from three different graphite materials. Height profile analysis shows that the individual exfoliated graphite oxide nanosheets have thickness of approximately $1 \mathrm{~nm}$, indicating exfoliation of graphite oxide into single layers. The lateral size of graphite oxide nanosheets ranged from a few tenths of nanometers to over few tenths of micrometers, reflecting the particle size of the starting graphite materials (Table 1).

The Pt loading calculated from the mass loss observed by thermogravimetry under oxidizing conditions were in agreement with the nominal content (Table 1). XRD
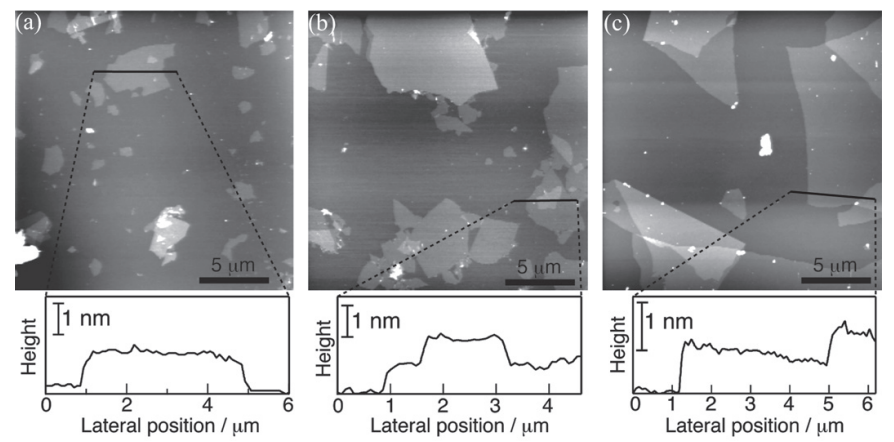

Fig. 1 AFM images of exfoliated graphite oxide nanosheets obtained from (a) small, (b) medium, and (c) large sized graphite deposited on a silicon substrate.
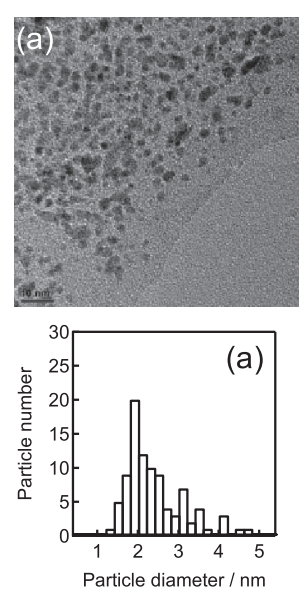

(a)

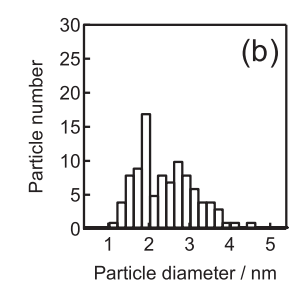

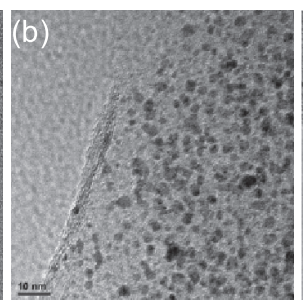

(b)

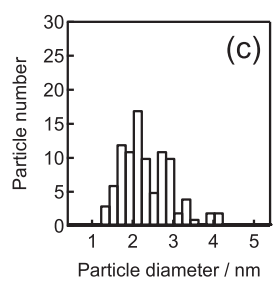

Fig. 2 TEM images and Pt particle-sizes histograms of 20 mass \% Pt/graphene derived from (a) small, (b) medium, and (c) large sized graphite.

measurements (data not shown) of Pt/graphene exhibited broad reflections at $d=0.38$ and $0.23 \mathrm{~nm}$, which are attributed to the disordered graphite-like structure of restacked graphene and Pt(111), respectively. High resolution TEM images showed highly dispersed Pt nanoparticles with average diameter of $2.2 \mathrm{~nm}$, irrespective of the size of graphene (Fig. 2).

Cyclic voltammograms in de-aerated $0.1 \mathrm{M} \mathrm{HClO}_{4}(60$ ${ }^{\circ} \mathrm{C}$ ) are shown in Fig. 3 . The electrochemically active $\mathrm{Pt}$ surface area (ECSA) was independent on the size of graphene (Table 1), in agreement with the TEM observations. Linear sweep voltammograms for the three electrocatalysts in $\mathrm{O}_{2}$-saturated electrolyte are illustrated in Fig. 4. The mass and surface area normalized kinetic current $j_{\mathrm{k}}$ (mass activity and specific activity) obtained from the Koutecky-Levich plots at 800 and $850 \mathrm{mV}$ vs. RHE are given in Table 1. Despite the small particle size and suitable surface area of the prepared electrocatalysts, the activity of $\mathrm{Pt} /$ graphene is at least 10 times lower than commercial platinum loaded carbon black catalyst with similar Pt geometry. Although the particle size and ECSA of Pt in the three electrocatalysts were comparable, a large difference in the ORR activity was observed for the different size graphene used. The $j_{\mathrm{k}}$ values increased with the decrease in the size of graphene, 


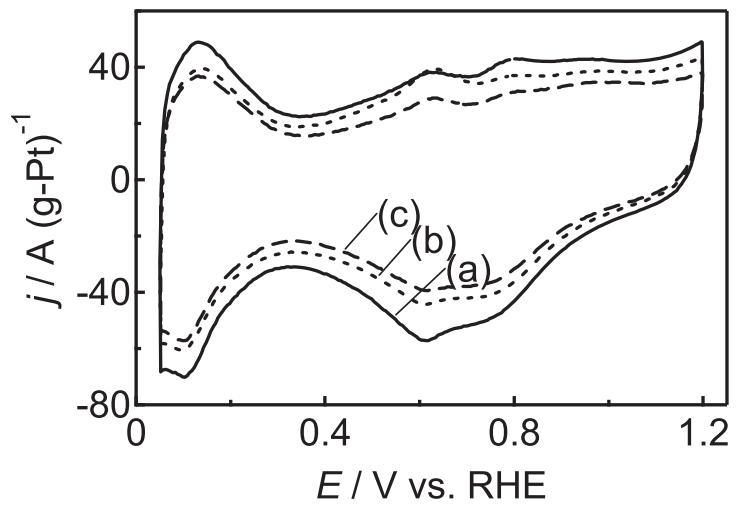

Fig. 3 Cyclic voltammograms of 20 mass \% Pt/graphene derived from (a) small, (b) medium, and (c) large graphite in $0.1 \mathrm{M} \mathrm{HClO}_{4}\left(60{ }^{\circ} \mathrm{C}\right)$ at $50 \mathrm{mV} \mathrm{s}^{-1}$.

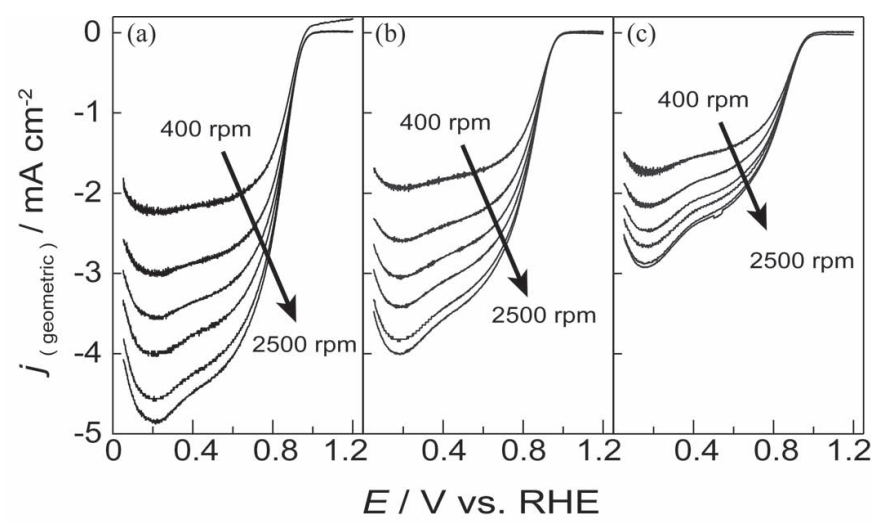

Fig. 4 Linear sweep voltammograms of 20 mass \% Pt/ graphite derived from (a) small, (b) medium, and (c) large graphite in $0.1 \mathrm{M} \mathrm{HClO}_{4}\left(60{ }^{\circ} \mathrm{C}\right)$ at $10 \mathrm{mV} \mathrm{s}^{-1}$ and $\omega=400$, 800, 1200, 1600, 2200, $2500 \mathrm{rpm}$.

with Pt/graphene-S exhibiting 2.5 times higher activity than $\mathrm{Pt} /$ graphene-L. We tentatively attribute this unexpected trend to the unique structure of the Pt/graphene prepared in this study. The one-step hydrogen reduction process of the $\mathrm{Pt}$ precursor and graphite oxide nanosheet mixture will result in a composite with $\mathrm{Pt}$ nanoparticles embedded in the slit-shaped micropores of aggregated graphene. Since the measured ECSA is reasonable for Pt nanoparticles of a few nanometers, most of the Pt nanoparticles should be in contact with the aqueous electrolyte. However, due to diffusion limitations of $\mathrm{O}_{2}$ into the micropores of graphene aggregates, a large portion of the Pt nanoparticles embedded deeply in the aggregated restacked graphene structure are most likely not available for the ORR. $\mathrm{O}_{2}$ diffusion within such micropores should not be strongly affected by hydrodynamic conditions, i.e. the rotating speed should have little effect into the diffusion of $\mathrm{O}_{2}$ into micropores with long diffusion length. This will explain the observation of limiting current only at low rotation speeds. As the $\mathrm{O}_{2}$ diffusion path will be longer for larger sized graphene, the amount of inactive $\mathrm{Pt}$ for the ORR will increase. In other words, only Pt nanoparticles near the edges of graphene are electrochemically active for ORR.
The decrease in specific activity with the increase in graphene size is in agreement with the above assumption. The results obtained in this work clearly illustrate the importance of the structure of $\mathrm{Pt} / \mathrm{C}$ for full utilization of the electrocatalyst.

\section{Conclusion}

We have synthesized graphite oxide nanosheets with three different sheet sizes. Pt/graphene (20 mass \% Pt) was prepared by mixing $\mathrm{Pt}\left(\mathrm{NO}_{2}\right)_{2}\left(\mathrm{NH}_{3}\right)_{2}$ with graphite oxide nanosheet and subsequent reduction at $200{ }^{\circ} \mathrm{C}$. AFM images confirmed the preparation of single-layer graphite oxide, and TEM images revealed well dispersed Pt nanoparticles. Despite the similarity in Pt nanoparticle size $(2.2 \mathrm{~nm})$ and surface area $\left(\sim 50 \mathrm{~m}^{2} \mathrm{~g}^{-1}\right)$, the three catalysts exhibited different oxygen reduction reaction activity; the activity was strongly affected by the size of graphene. Smaller sized graphene afforded higher mass and specific activity towards the oxygen reduction reaction than when larger sized graphene was used. The results were discussed in terms of the slow $\mathrm{O}_{2}$ diffusion through the micropores of aggregated graphene. The importance of the structure of $\mathrm{Pt} / \mathrm{C}$ for full utilization of the electrocatalyst has been demonstrated. The tailoring of $\mathrm{Pt} /$ graphene mesostructure is expected to afford enhanced electrocatalytic activity.

\section{Acknowledgements}

This work was supported in part by a Grant-in-Aid for Scientific Research (21685025), a Global COE Program by the Ministry of Education, Culture, Sports, Science and Technology, and a "Special Coordination Funds for Promoting Science and Technology, Creation of Innovation Centers for Advanced Interdisciplinary Research Areas" Project from JST. This article is dedicated to the first principal, Chotaro Harizuka, on the occasion of the $100^{\text {th }}$ anniversary of the Faculty of Textile Science and Technology, Shinshu University.

\section{References}

1) S. Park and R. S. Ruoff, Nature Nanotechnol., 4, 217 (2009).

2) A. K. Geim, Science, 324, 1530 (2009).

3) S. Stankovich, D. A. Dikin, G. H. B. Dommett, K. M. Kohlhaas, E. J. Zimney, E. A. Stach, R. D. Piner, S. T. Nguyen, and R. S. Ruoff, Nature, 442, 282 (2006).

4) S. Stankovich, D. A. Dikin, R. D. Piner, K. A. Kohlhaas, A. Kleinhammes, Y. Jia, Y. Wu, S. T. Nguyen, and R. S. Ruoff, Carbon, 45, 1558 (2007).

5) Y. Si and E. T. Samulski, Chem. Mater, 20, 6792 (2008).

6) E. Yoo, T. Okata, T. Akita, M. Kohyama, J. Nakamura, and I. Honma, Nano Lett., 9, 2255 (2009).

7) R. Kou, Y. Shao, D. Wang, M. H. Engelhard, J. H. Kwak, J. Wang, V. V. Viswanathan, C. Wang, Y. Lin, Y. Wang, I. A. Aksay, and J. Liu, Electrochem. Commun., 11, 954 (2009).

8) J. Sato, Y. Takasu, K. Fukuda, and W. Sugimoto, Chem. Lett., 40, 44 (2011).

9) W. S. Hummers and R. E. Offeman, J. Am. Chem. Soc., 80, 1339 (1958). 